\title{
Papers
}

\section{Plasminogen activator system, vascular endothelial growth factor, and colorectal cancer progression}

\author{
E A Baker, F G Bergin, D J Leaper
}

\begin{abstract}
Aims-The plasminogen activator system (PAS) consists of the plasminogen activators (urokinase (uPA) and tissue-type (tPA) plasminogen activators), the uPA receptor (UPAR), and the plasminogen activator inhibitors (PAI-1 and PAI-2). Plasminogen activators activate plasminogen to plasmin, which can break down extracellular matrix (ECM) components. Vascular endothelial growth factor (VEGF) is a mitogen for endothelial cells and is involved in angiogenesis. VEGF has been shown to upregulate UPA and this may facilitate tumour angiogenesis further.

Methods-PAS components and VEGF were determined by enzyme linked immunosorbent assay (ELISA) in paired colorectal tumour and normal tissue $(n=50)$ and correlated with pathological staging.
\end{abstract}

Results-uPA, UPAR, PAI-1, and VEGF values were significantly higher in tumour tissue (for example, tumour uPA: median, 2.3 (range, $0.1-6.7$ ) $\mathrm{ng} / \mathrm{mg}$ protein $v$ normal uPA: median, 0.2 (range, 0-2.6) ng/mg protein). tPA was significantly higher in normal mucosa and there was no difference in PAI-2. UPA, UPAR, PAI-1, and VEGF values significantly correlated with each other and with Dukes's staging (uPA in adenomas: median, 0.42 (range, 0.11.2) $\mathrm{ng} / \mathrm{mg}$ protein; upA in Dukes's B tumours: median, 2.1 (range, 0.4-4.3) ng/ mg protein; and uPA in Dukes's D tumours: median, 4.0 (range, 3.7-4.2) ng/mg protein) and lymphatic invasion. In addition PAI-1 also correlated with tumour size and differentiation.

Conclusion-The involvement of the PAS and VEGF in colorectal cancer appears to be complex. uPA, uPAR, PAI-1, and VEGF were upregulated in tumour tissue and this correlated with Dukes's staging and lymphatic invasion.

(f Clin Pathol: Mol Pathol 2000;53:307-312)

Keywords: plasminogen activators; vascular endothelial growth factor; colorectal cancer

Angiogenesis is important for tumour growth and metastasis. ${ }^{12}$ The formation of tumour microvessels is stimulated by angiogenic factors such as vascular endothelial growth factor (VEGF) and basic fibroblast growth factor (bFGF). ${ }^{2}$ VEGF is a $45 \mathrm{kDa}$ glycoprotein that is mitogenic for endothelial cells. It binds to specific receptors on endothelial cells, where it induces endothelial proliferation and capillary tube formation, enhancing tumour neovascularisation or angiogenesis. Previous studies have shown that overexpression of VEGF correlated with the progression of human malignancies, including colorectal cancer. ${ }^{3}{ }^{4}$ The properties of VEGF have been reviewed elsewhere. $^{56}$

Tumour invasion and metastasis is a complex process involving many sequential, interrelated events including angiogenesis, intravasation, and extravasation. Many of these stages, including angiogenesis, involve the controlled degradation of extracellular matrix (ECM) components by proteinases. The extracellular proteinases involved in ECM degradation are the matrix metalloproteinases (MMPs) and the serine proteinases.

The plasminogen activator system (PAS) consists of two serine proteinases, plasminogen activators, urokinase-type (uPA) and tissuetype (tPA), the plasminogen activator inhibitors 1 and 2 (PAI-1 and PAI-2), and the receptor for urokinase type plasminogen activator (UPAR). The plasminogen activators, as the name suggests, convert inactive plasminogen to the active serine proteinase, plasmin. Plasmin is 4 July 2000

Table 1 Conditions for performing the plasminogen activator system and vascular endothelial growth factor (VEGF) ELISAs

\begin{tabular}{|c|c|c|c|c|c|c|}
\hline ELISA & Dilution & Capture antibody & Incubation & Detection antibody & Conjugate & Standard curve \\
\hline $\mathrm{uPA}$ & $1 / 10$ & Mouse antihuman & Overnight $4^{\circ} \mathrm{C}$ & Biotinylated antihuman uPA & Streptavidin-HRP & $0.1-1.0 \mathrm{ng} / \mathrm{ml}$ \\
\hline tPA & None & Goat anti-tPA & 1 hour RT shaking & - & HRP anti-tPA & $0.5-10.0$ \\
\hline UPAR & $1 / 5$ & Mouse antihuman & Overnight $4^{\circ} \mathrm{C}$ & Biotinylated antihuman UpaR & Streptavidin-HRP & $0.1-3.0 \mathrm{ng} / \mathrm{ml}$ \\
\hline PAI-1 & $1 / 10$ & Mouse antihuman & Overnight $4^{\circ} \mathrm{C}$ & Biotinylated antihuman PAI-1 & Streptavidin-HRP & $0.1-10.0 \mathrm{ng} / \mathrm{ml}$ \\
\hline PAI-2 & None & Polyclonal antihuman & 2 hours RT & Biotinylated antihuman PAI-2 & Streptavidin-HRP & $0.5-10 \mathrm{ng} / \mathrm{ml}$ \\
\hline VEGF & None & Mouse antihuman & 2 hours RT & - & HRP anti-VEGF & $31.2-2000 \mathrm{pg} / \mathrm{ml}$ \\
\hline
\end{tabular}

ELISA, enzyme linked immunosorbent assay; HRP, horseradish peroxidase; PAI, plasminogen activator inhibitor; RT, room temperature; tPA, tissue type plasminogen activator; uPA, urokinase plasminogen activator. 
Table 2 Differences in plasminogen activator, PAI and uPAR (ng/mg protein), and VEGF (pg/mg protein) values in colorectal tumour and normal tissue samples

\begin{tabular}{lll}
\hline & Tumour & Normal \\
\hline uPA & $2.3^{\star}(0.1-6.7)$ & $0.2(0-2.6)$ \\
tPA & $3.3^{\star}(0.1-23.8)$ & $6.8^{\star}(1.1-37.5)$ \\
uPAR & $2.2^{\star}(0.2-14.0)$ & $0.6(0.2-4.1)$ \\
PAI-1 & $9.8^{\star}(0.2-62.4)$ & $2.0(0.1-20.7)$ \\
PAI-2 & $1.0(0-7.3)$ & $0.7(0-4.7)$ \\
VEGF & $189^{\star}(30-4156.0)$ & $27(3-108)$ \\
\hline
\end{tabular}

PAI, plasminogen activator inhibitor; PAR, plasminogen activator receptor; tPA, tissue type plasminogen activator; uPA, urokinase plasminogen activator; VEGF, vascular endothelial growth factor.

Values are expressed as median with the range in parentheses. ${ }^{\star} \mathrm{p}<0.0001$, Mann Whitney.

involved in ECM degradation directly because it is a broad substrate proteinase that can degrade most proteins within the ECM (for example, fibronectin, laminin, and proteoglycans). ${ }^{7}$ Plasmin also acts on the ECM indirectly by activating the latent forms of several MMPs (for example, MMP-1).

The function and regulation of PAS components has been reviewed elsewhere. ${ }^{7-9}$ In brief, the two plasminogen activators differ in biological function and distribution; uPA is important in tissue degradation in both physiological and pathological processes, ${ }^{7}{ }^{10}$ whereas tPA is important in fibrinolysis. ${ }^{8}$ The plasminogen activators also differ in inhibitory functions. PAI-1 inhibits both uPA and tPA; however, PAI-2 inhibits only uPA. In vivo it is the balance between plasminogen activators and their inhibitors that determines matrix
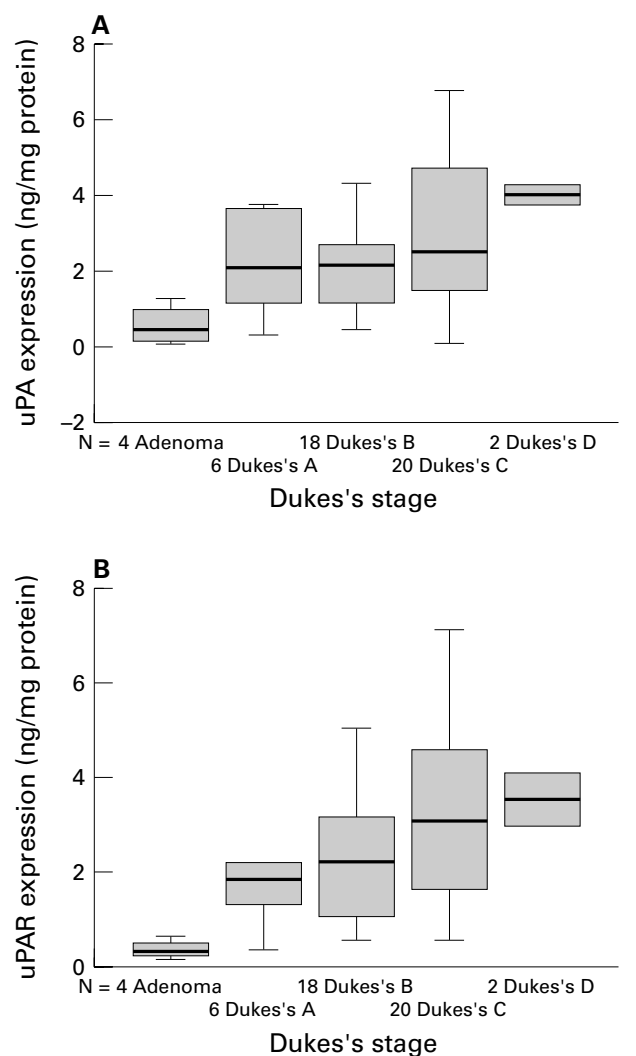

Figure 1 Box plots showing the positive correlation between $(A)$ urokinase plasminogen activator (uPA), (B) the uPA receptor (UPAR), (C) plasminogen activator inhibitor 1 (PAI-1), and (D) vascular endothelial growth factor (VEGF) values with the Dukes's stage of the tumour (median and interquartile range) in colorectal cancer tissue $\left({ }^{\star} p<0.05\right.$, Spearman's correlation). The line within the box plot corresponds to the median value.

degradation by plasmin. The function of the $\mathrm{uPA}$ receptor is to focus the proteolytic potential of the tumour cells, thereby enhancing invasion. ${ }^{11}$

The PAS has been studied extensively in various human cancers. Combinations of these components, in particular uPA and PAI-1, have been found to be of prognostic relevance in several human cancers, including colorectal ${ }^{1213}$ and breast cancer. ${ }^{14} 15$

Most previous studies in colorectal cancer have determined the expression of individual components, ${ }^{13} 1617$ or related the expression of PAS components to specific histological grades. ${ }^{18} 19$

In addition to VEGF expression correlating with tumour progression, several studies have also found VEGF to increase both uPA and uPAR on endothelial cells in vitro, ${ }^{20}{ }^{21}$ and to correlate with $\mathrm{uPA}^{22}$ and $\mathrm{uPAR}^{23}$ expression in vivo.

Our study aims to determine the concentrations of VEGF and the five components of the PAS in paired colorectal tumour and normal tissue samples and correlate these with the clinical pathological grade of the tumour.

\section{Methods}

MATERIALS

Enzyme linked immunoassay (ELISA) kits for uPA, tPA, uPAR, PAI-1, and PAI-2 were purchased from American Diagnostica (Greenwich, USA) and for VEGF from R\&D Systems (Abingdon, UK). Phosphate buffered
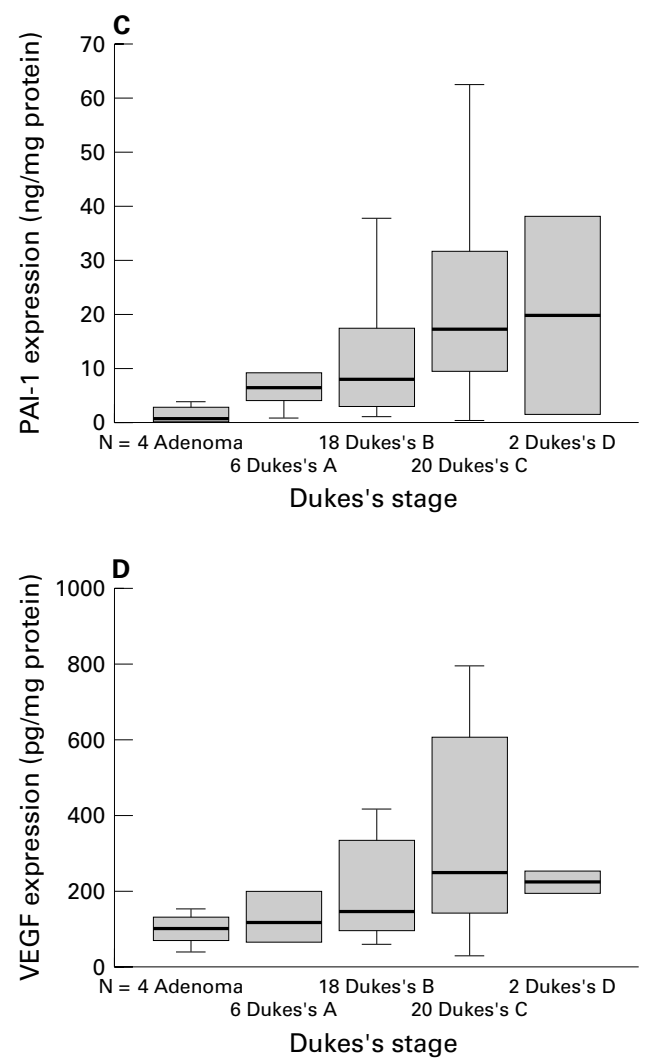


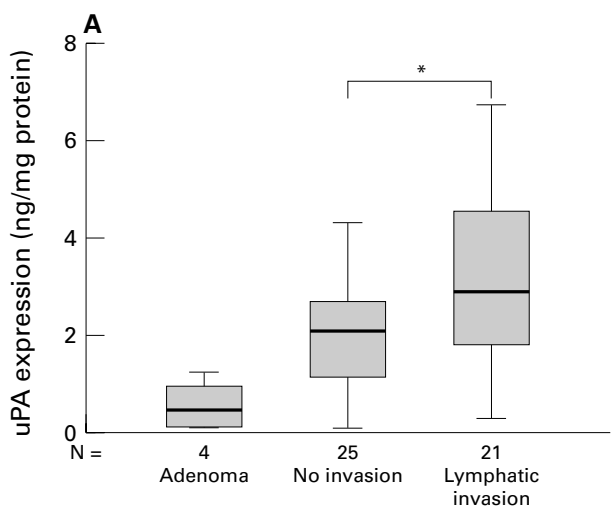

Lymphatic invasion

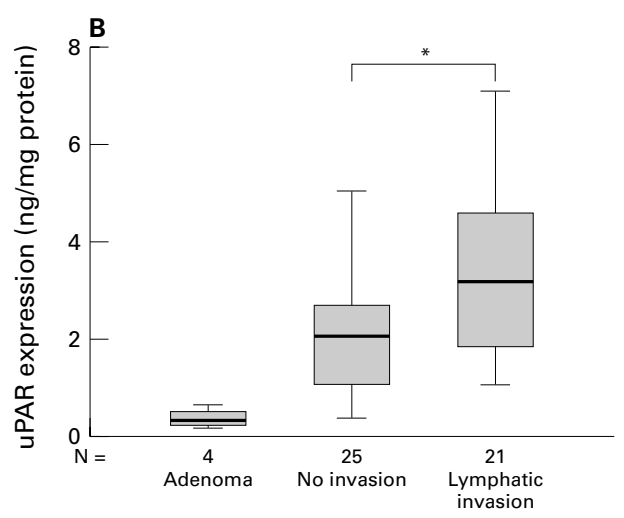

Lymphatic invasion

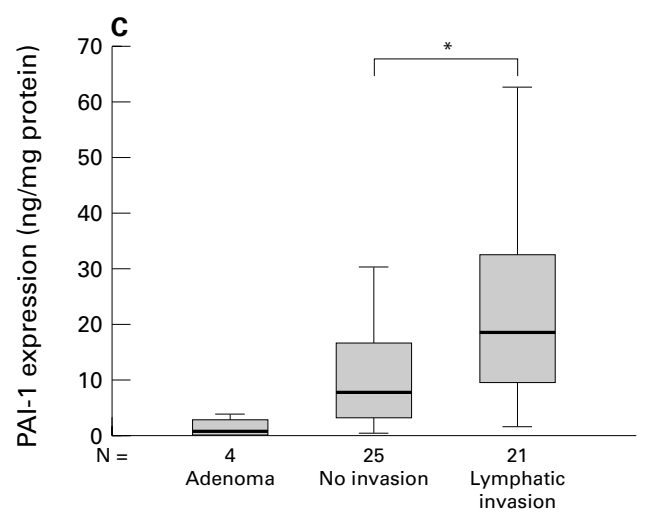

Lymphatic invasion

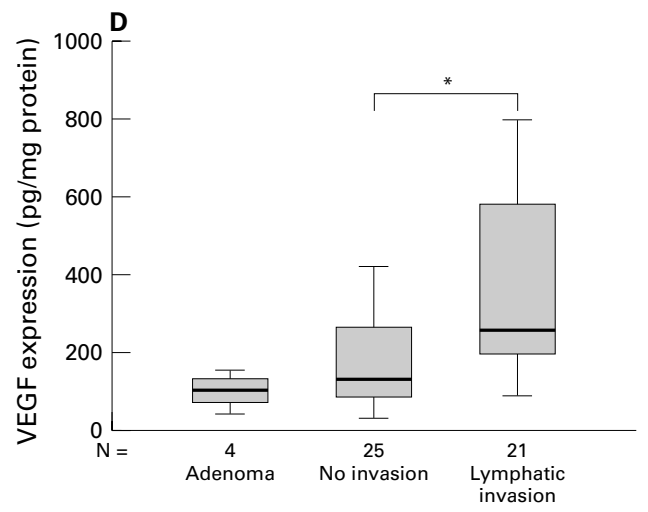

Lymphatic invasion

Figure 2 Box plots showing the positive correlations between $(A)$ urokinase plasminogen activator $(u P A),(B)$ the $u P A$ receptor (UPAR), (C) plasminogen activator inhibitor 1 (PAI-1), and (D) vascular endothelial growth factor (VEGF) values and lymphatic invasion (median and interquartile range). Expression was significantly greater in tumours that had undergone lymphatic invasion ( ${ }^{\star} p<0.05$, Spearman's correlation). The line within the box plot corresponds to the median value.

saline (PBS), total protein assay, and sulphuric acid were from Sigma Aldrich (Poole, Dorset, UK).

PATIENTS AND TISSUE SAMPLES

Colorectal specimens were collected from the operating theatre and taken to the department of pathology, North Tees General Hospital. Paired tissue samples (tumour margin and normal colon) were obtained by a consultant histopathologist within 30 minutes of surgical resection. Fifty paired colorectal tissue samples were obtained from consecutive patients between April 1998 and June 1999.

Each tissue sample was finely diced with a scalpel, homogenised (Polytron PT 2,100; Kinematica; Philip Harris Scientific, Lichfield, UK) in PBS for five minutes, and centrifuged for 15 minutes at $750 \times g$. The homogenate was removed and stored in aliquots at $-80^{\circ} \mathrm{C}$ until analysis. The total protein concentration of each tissue sample was determined by the method of Ohnishi and Barr.

All the colorectal tumours were classified according to their pathological staging: Dukes's stage, differentiation, tumour depth, and whether the tumour had undergone lymphatic and/or vascular invasion.
ENZYME LINKED IMMUNOSORBENT ASSAYS

The concentrations of uPA, tPA, uPAR, PAI-1, PAI-2, and VEGF were measured by enzyme immunoassay kits. Table 1 summarises the required dilutions, antibodies, conditions, and detection ranges for each ELISA. The concentration of each protein was measured at $450 \mathrm{~nm}$ on a microplate reader (Dynex Technologies, Billinghurst, UK). Values for the PAS components $(\mathrm{ng} / \mathrm{ml})$ and VEGF $(\mathrm{pg} / \mathrm{ml})$ were determined for each sample from a standard curve using Revelation Software (Dynex Technologies, Billinghurst, UK). Final tissue values were expressed as $\mathrm{ng} / \mathrm{mg}$ protein or $\mathrm{pg} / \mathrm{mg}$ protein for PAS components and VEGF, respectively.

\section{STATISTICAL ANALYSIS}

For comparisons between concentrations in colorectal tumour and normal tissue samples the Mann Whitney U test for non-parametric data, with $95 \%$ confidence limits, was performed. Spearman's correlation coefficient was used to determine whether a correlation existed between these components and clinical pathological staging (Dukes's stage, tumour depth, differentiation, and vascular and lymphatic invasion). The data were considered to be significant at $\mathrm{p}<0.05$. 


\section{Results}

In our study, paired colorectal tissues (tumour and normal mucosa) from 50 patients were analysed for expression of VEGF and components of the PAS. Histologically, four tumours were tubular adenomas, six were Dukes's A, 18 Dukes's B, 20 Dukes's C, and two Dukes's D tumours. Eleven patients had well differentiated, 28 moderately, and six poorly differentiated tumours. Twenty one of 46 tumours had undergone lymphatic invasion (lymphatic vessel invasion at the site of the primary tumour), and 13 of 46 had undergone vascular invasion at the time of resection.

EXPRESSION OF PAS COMPONENTS

$u P A$

uPA values were significantly higher in tumour tissue (median, $2.3 \mathrm{ng} / \mathrm{mg}$ protein; range, $0.1-6.7)$ than in the corresponding normal tissue (median, $0.2 \mathrm{ng} / \mathrm{mg}$ protein; range, $0-2.6$; $\mathrm{p}<0.0001$, Mann Whitney; table 2).

tPA

tPA values were significantly higher in normal colorectal tissue (median, $6.8 \mathrm{ng} / \mathrm{mg}$ protein; range, 1.1-37.5) than in the tumour tissues (median, $3.3 \mathrm{ng} / \mathrm{mg}$ protein; range, 0.1-23.8; $\mathrm{p}<0.0001$, Mann Whitney U; table 2).

UPAR

Values for the uPA receptor were significantly higher in colorectal tumour tissue (median, $2.2 \mathrm{ng} / \mathrm{mg}$ protein; range, $0.2-14$ ) than in normal colon tissue (median, $0.6 \mathrm{ng} / \mathrm{mg}$ protein; range, $0.2-4.1 ; \mathrm{p}<0.0001$, Mann Whitney U; table 2).

PAI-1

PAI-1 values were significantly higher in tumour tissue (median, $9.8 \mathrm{ng} / \mathrm{mg}$ protein; range, 0.2-62.4) than in normal colorectal tissue (median, $2.0 \mathrm{ng} / \mathrm{mg}$ protein; range, $0.1-$ 20.7; p < 0.0001, Mann Whitney; table 2).

PAI-2

Although PAI-2 values were greater in tumour tissue (median, $1.0 \mathrm{ng} / \mathrm{mg}$ protein; range, 0-7.3) than in normal mucosa (median, $0.7 \mathrm{ng} / \mathrm{mg}$ protein; range, $0-4.7$ ) the difference was not significant (table 2).

VEGF

VEGF values were significantly higher in tumour tissue (median, $189 \mathrm{pg} / \mathrm{mg}$ protein; range, 307-4156) than normal colorectal tissue (median, $27.3 \mathrm{pg} / \mathrm{mg}$ protein; range, 3-108; $\mathrm{p}<0.0001$, Mann Whitney U; table 2).

CORRELATIONS BETWEEN PAS COMPONENTS AND VEGF

UPA, UPAR, PAI-1, and VEGF values within colorectal tumour tissue correlated significantly with each other (Spearman's correlation, $\mathrm{p}<0.05)$. In addition, VEGF expression correlated with PAI-2 expression.

PAS, VEGF, AND PATHOLOGICAL STAGE

The expression of VEGF and the components of the PAS were correlated with the clinical
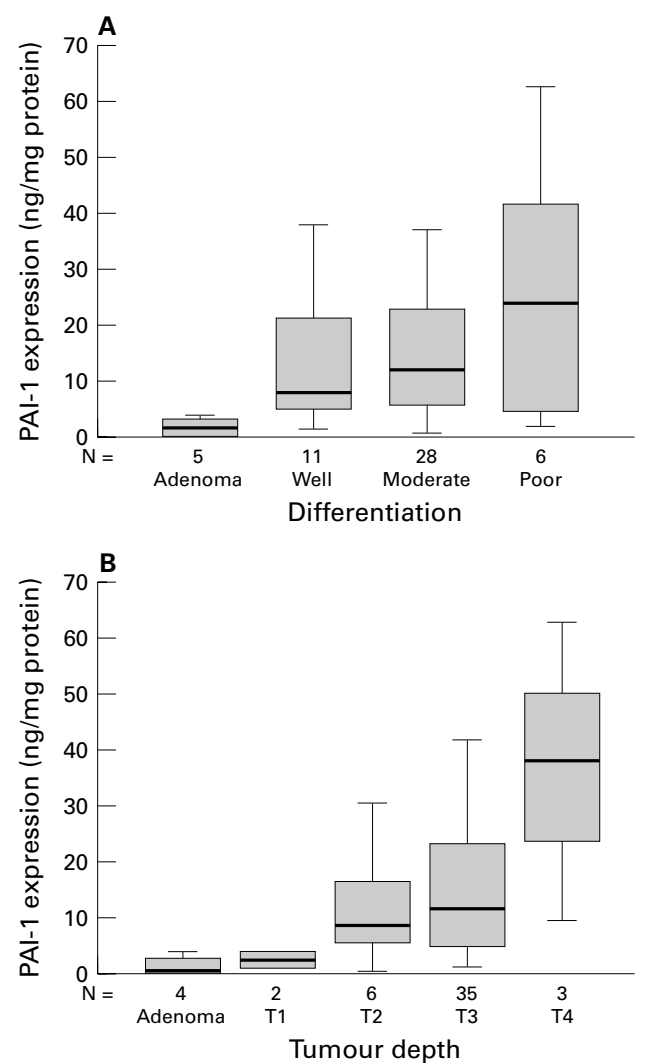

Figure 3 Box plots showing the positive correlation between plasminogen activator inhibitor 1 (PAI-1) values and $(A)$ tumour differentiation and (B) tumour size (median and interquartile range). ${ }^{\star} p<0.05$ Spearman's correlation. The line within the box plot corresponds to the median value.

pathological stage of the tumour; that is, Dukes's stage, tumour differentiation, tumour depth $\left(\mathrm{T}_{1}-\mathrm{T}_{4}\right)$, and finally whether the tumour had undergone lymphatic and/or vascular invasion.

Three components of the PAS (uPA, UPAR, and PAI-1), as well as VEGF, significantly correlated with tumour stage. These four factors correlated with the Dukes's stage of the tumour (fig 1) and lymphatic invasion (fig 2). In addition, the expression of PAI-1 also correlated with tumour differentiation and tumour depth (fig 3).

\section{Discussion}

The involvement of the PAS in colorectal cancer progression appears to be complex. In agreement with previous studies, values for uPA, ${ }^{19}{ }^{25-29}$ its receptor uPAR, ${ }^{19}$ and the inhibitor, PAI-1, ${ }^{19}{ }^{29}$ were higher in colorectal tumours than in the corresponding normal mucosa. However, tPA values were higher in normal colorectal tissue. ${ }^{19} 2930$ This differential expression of uPA and tPA in tumour and normal tissue confirms their different roles in plasminogen activation in vivo: $\mathrm{uPA}$ is involved in tissue degradation and tPA in fibrinolysis.

The balance between the expression of the activators and inhibitors is important in vivo in determining whether matrix degradation and activation of other proteinases is likely to occur. In our present study, both uPA and the inhibitor PAI-1 were greater in colorectal 
tumour tissue than in normal tissue. However, previous studies have shown that this increased PAI-1 expression does not significantly inhibit uPA activity in primary tumours; therefore, the balance will favour proteolysis. ${ }^{9}$

Within colorectal tumours there is a differential production and expression of PAS components: uPA and the PAIs are produced by stromal cells, whereas uPAR expression has been demonstrated on tumour cells. The increased expression of the receptor for uPA seen in colorectal tumours is thought to localise the proteolytic potential of the tumour cells and therefore their invasion. ${ }^{11}$

Our study has also demonstrated a significant correlation between uPA, uPAR, and PAI-1 and the pathological staging of the tumour; in particular, Dukes's staging and lymphatic invasion. Previous studies have shown conflicting results on the correlations between PAS components and tumour pathology. Previously, Suzuki and colleagues demonstrated that uPAR expression increased from adenomas through to invasive carcinomas. ${ }^{17}$ Another study found that uPA values at the tumour-host interface in Dukes's C tumours were twice those of Dukes's A tumours; uPAR was also significantly greater in Dukes's C tumours, but there was no significant difference in PAI-1 values. ${ }^{27}$ However, other studies found no correlation between uPA expression and tumour stage or the site of the tumour. ${ }^{1628}$

As well as their involvement in tumour progression, PAS components have also been implicated in cancer prognosis in colorectal ${ }^{13}$ and other cancers. ${ }^{14}{ }^{15}$ In colorectal cancer, uPA, ${ }^{18}{ }^{19}$ uPAR, $^{13}$ and PAI- ${ }^{12}$ expression in plasma has been associated with shorter survival. Furthermore, PAI-2 values in carcinomas and tPA concentrations in normal mucosa have been shown to have prognostic value on overall survival. ${ }^{19}$

In agreement with our results, it has been reported that VEGF expression (protein and mRNA) is significantly greater in colorectal tumour tissue than in normal tissue. ${ }^{31}{ }^{32} \mathrm{VEGF}$ expression was also found to be significantly greater in tumours with lymphatic invasion than in those without. ${ }^{23}$ It has been suggested that the involvement of VEGF in lymphatic invasion is similar to vascular angiogenesis, in that lymphatic endothelial cells may respond to VEGF by increasing angiogenesis within the lymphatics, thereby inducing metastasis via the lymphatics as well as via the blood vessels. ${ }^{33}$ Our study also found that VEGF values within tumour tissue significantly correlated with the Dukes's stage of the tumour. In addition, one previous study has shown a correlation between VEGF expression and tumour size. $^{31}$

Also in agreement with our results, the few studies that have compared the expression of VEGF with PAS components found a positive correlation between VEGF and both $\mathrm{uPA}^{22}$ and UPAR expression. ${ }^{23}$

Previously, studies have determined the expression of individual PAS components in colorectal cancer progression and or survival; however, there have been few studies determining the association of all PAS components with VEGF. Our results have demonstrated an increased coexpression of uPA, uPAR, PAI-1, and VEGF in colorectal tumour tissue compared with normal mucosa. A positive correlation was found between these PAS components (uPA, uPAR, PAI-1) and VEGF values, as well as with the pathological staging of colorectal cancer. UPA and VEGF are known to be involved in tumour angiogenesis, one of the initial stages of the metastatic cascade. However, further research is needed to determine their involvement in colorectal cancer invasion and metastasis. In addition, future follow up of the patients involved is required to determine the prognostic relevance of these factors.

1 Folkmann J. What is the evidence that tumours are angiogenesis dependent? F Natl Cancer Inst 1990;82:4-6. Folkmann J, Shing Y. Angiogenesis. f Biol Chem 1992;267: 10931-4.

3 Takahashi Y, Kitadai Y, Bucana CD, et al. Expression of vascular endothelial growth factor and its receptor, KDR, correlates with vascularity, metastasis and proliferation of human colon cancer. Cancer Res 1995;55:3964-8.

4 Kang SM, Maeda K, Chung YS, et al. Vascular endothelial growth factor expression correlates with haematogenous metastasis and prognosis in colorectal carcinoma. Oncol Rep 1997;4:381-4

5 Ferrara N, Houck K, Jakeman L, et al. Molecular and biological properties of the vascular endothelial growth biological properties of the vascular endothelial g
factor family of proteins. Endocr Rev 1992;13:18-32.

6 Ferrara N, Davis-Smith T. The biology of vascular endotheFerrara N, Davis-Smith T. The biology of vascul
lial growth factor. Endocr Rev 1997;18:4-25.

7 Dano K, Andreasen PA, Grondahl-Hansen J, et al. Plasminogen activators, tissue degradation and cancer. $A d v$ Cancer Res 1985;44:139-266.

8 Kluft C, Dooijewaard G, Emeis JJ. Role of the contact system in fibrinolysis. Semin Thromb Hemost 1987;13:50-68.

9 Gandolfo GM, Conti L, Vercillo M. Fibrinolysis components in breast cancer and colorectal carcinoma. Anticancer Res 1996;16:2155-60.

10 Jessup JM. Role of urokinase, its receptor and serpins in colorectal carcinoma. Gastroenterology 1994;107:1555-9.

11 Cohen RL, Xi XP, Crowley CW, et al. Effects of urokinase receptor occupancy on plasmin generation and proteolysis of basement membrane by human tumour cells. Blood 1991;78:479-87.

12 Nielsen HJ, Pappot H, Christensen IJ, et al. Association between plasma concentrations of plasminogen activator inhibitor-1 and survival in patients with colorectal cancer. BMF 1998;316:829-30

13 Stephens RW, Nielsen HJ, Thorlacius-Ussing O, et al. Plasma urokinase receptor levels in patients with colorectal cancer: relationship to poor prognosis. $\mathcal{F}$ Natl Cancer Inst 1999;91:869-74

14 Duffy MJ, Reilly D, O' Sullivan C, et al. Urokinase plasminogen activator and prognosis in breast cancer. Lancet 1990;335:108-11

15 Bouchet C, Spyratos F, Martin PM, et al. Prognostic value of urokinase type plasminogen activator and plasminogen activator inhibitors PAI-1 and PAI-2 in breast carcinomas. Br F Cancer 1994;69:398-405.

16 Berney CR, Yang JL, Fisher RJ, et al. Correlates of urokinase-type plasminogen activator in colorectal cancer: positive relationship with $\mathrm{nm} 23$ and c-erbB-2 protein positive relationship with $\mathrm{nm} 23$ and
expression. Oncol Res 1998;10:47-54.

17 Suzuki S, Hayashi Y, Wang Y, et al. Urokinase type plasminogen activator receptor expression in colorectal plasminogen activator receptor

18 Mulcahy HE, Duffy MJ, Gibbons D, et al. Urokinase-type plasminogen activator and outcomes in Dukes' B colorectal

19 Ganesh S, Sier CFM, Heerding MM, et al. Contribution of plasminogen activators and their inhibitors to the survival prognosis of patients with Dukes' stage B and C colorectal cancer. Br f Cancer 1997;75:1793-801.

20 Pepper MS, Ferrara N, Orci L, et al. Vascular endothelial growth factor (VEGF) induces plasminogen activators and plasminogen activator inhibitor-1 in microvascular endothelial cells. Biochem Biophys Res Commun 1991;181: 902-6.

21 Mandriota SJ, Seghezzi G, Vassalli JD, et al. Vascular endothelial growth factor increased urokinase receptor expression in vascular endothelial cells. f Biol Chem 1995; 270:9709-16.

22 Berney CR, Yang JL, Fisher RJ, et al. Vascular endothelial growth factor expression is reduced in liver metastasis growth factor expression is reduced in liver metastasis
from colorectal cancer and correlates with urokinase type plasminogen activator. Anticancer Res 1998;18: type plas $973-8$. 
23 Nakata S, Ito KI, Fujimori M, et al. Involvement of vascular endothelial growth factor and urokinase type plasminogen activator receptor in microvessel invasion in human colorectal cancers. Int 7 Cancer 1998;79:179-86.

24 Ohnishi ST, Barr JK. A simplified method of quantifying proteins using the biuret and phenol reagents. Anal Biochem 1978;86:193-200.

25 Grondahl-Hansen J, Ralfkiaer E, Kirkeby LT, et al. Localisation of urokinase type plasminogen activator in stromal cells in adenocarcinomas of the colon in humans. $A m \mathcal{F}$ Pathol 1991;138:111-17.

26 Pyke C, Kristensen P, Ralfkiaer E, et al. Urokinase-type plasminogen activator is expressed in stromal cells and its receptor in cancer cells at invasive foci in human colon adenocarcinomas. Am 7 Pathol 1991;138:1059-67.

27 Buo L, Meling GI, Karlsrud TS, et al. Antigen levels of urokinase plasminogen activator and its receptor at the 作 related to tumour aggressiver $1133-8$.
28 Skelly MM, Troy A, Duffy MJ, et al. Urokinase-type plasminogen activator in colorectal cancer: relationship with clinicopathological features and

Cancer Res 1997;3:1837-40.
29 Protiva P, Sordat I, Chaubert P, et al. Alterations in plasminogen activation with epithelial cell dysplasia grading in colorectal adenomas. Br f Cancer 1998;77:297-304.

30 Sier CFM, Verspaget HV, Griffioen G, et al. Imbalance of plasminogen activators and their inhibitors in human colorectal neoplasia. Implication of urokinase in colorectal carcinogenesis. Gastroenterology 1991;101:1522-58.

31 Konno H, Tanaka T, Baba M, et al. Quantitative analysis of vascular endothelial growth factor in colon cancer. Eur Surg Res 1998;30:273-8.

32 Wong MP, Cheung N, Yuen ST, et al. Vascular endothelial growth factor is up-regulated in early pre-malignant stage of colorectal tumour progression. Int 7 Cancer 1999;81:845-50.

33 Pepper MS, Wasi S, Ferrara N, et al. In vitro angiogenic and proteolytic properties of bovine lymphatic endothelial cells. proteolytic properties of bovine
Exp Cell Res 1994;210:298-305. 